\title{
AÇÃO DE HERBICIDAS AUXÍNICOS NO CONTROLE DE GUANXUMA (Sida glaziovii) EM PASTAGEM DE Urochloa decumbens
}

PRUDENCIO, Marcelo Falaci ${ }^{1}$

ANDREANI JÚNIOR, Roberto

RESUMO: A espécie (Sida glaziovii), vulgarmente conhecida com guanxuma branca, caule revestido por pubescência esbranquiçada e folhas lanuginosas. Os herbicidas mimetizadores de auxina mais importantes incluem os ácidos clorofenóxi (ex. 2,4-D), ácidos benzóicos (dicamba), piridinas (picloram, aminopiralide, triclopir e fluroxipir) e os ácidos quinolina carboxílicos (quinmerac, quinclorac). Eles basicamente mimificam os efeitos de concentrações de auxinas endógenas. O objetivo do presente trabalho foi o de avaliar a atuação dos herbicidas mimetizadores de auxina no controle da guanxuma branca em área de pastagem de Urochloa decumbens. Cada parcela constou de $5 \mathrm{~m}$ de comprimento e $5 \mathrm{~m}$ de largura, totalizando $25 \mathrm{~m}^{2}$ de área aplicada. O delineamento experimental foi em blocos casualizados com cinco tratamentos, e quatro repetições. A eficiência dos herbicidas no controle da planta daninha foi avaliada aos 5, 10, 15, 20, 25 e 30 dias após a aplicação (DAA), onde se utilizou uma escala visual de controle de $0 \%$ a $100 \%$. Os herbicidas Truper e Dominum, já apresentam controle satisfatório ente 80-89\% logo aos 5 DAA e com 15 DAA as plantas de guanxuma apresentavam-se com 90-100\% de controle. Os herbicidas Jaguar e Tordon obtiveram controle de $80 \%$ a partir dos 20 dias. Os herbicidas Truper, Jaguar, Tordon e Dominum nas doses recomendadas foram eficientes no controle da guanxuma branca.

Palavras chave: Mimetizadores dee Auxinas. Invasoras. Fitoxicidade.

\section{ACTIONOF AUXINIC HERBICIDES IN THE CONTROL (Sida glaziovii) GRAZING Urochloa decumbens PASTURE}

\begin{abstract}
SUMMARY: The species (Sida glaziovii), commonly known as white guanxuma, a white pubescence-coated stem and lanuginous leaves. The most important auxin mimic herbicides include chlorophenoxy acids (ex. 2,4-D), benzoic acids (dicamba), pyridines (picloram, aminopyralide, triclopyr and fluroxypyr) and quinoline carboxylic acids (quinmerac, quinclorac). They basically mimic the effects of endogenous auxin concentrations. The objective of this work was to evaluate the performance of auxin mimic herbicides in the control of white guanxuma in the pastureland of Urochloa decumbens. Each plot consisted of $5 \mathrm{~m}$ in length and $5 \mathrm{~m}$ in width, totaling $25 \mathrm{~m}^{2}$ of applied area. The experimental design was a randomized block with five treatments and four replications. Herbicide efficiency in weed control was evaluated at 5, 10, 15, 20, 25 and 30 days after application (DAA), where a visual control scale of $0 \%$ to $100 \%$ was used. The herbicides Truper and Dominum, already have satisfactory control between $80-89 \%$ at 5 DAA and with 15 DAA the guanxuma plants presented with $90-100 \%$ control. The herbicides Jaguar and Tordon obtained $80 \%$ control from the 20 days. The herbicides Truper, Jaguar, Tordon and Dominum at the recommended doses were efficient in the control of white guanxuma.
\end{abstract}

Keywords: Mimics Auxin. Invasive. Fitoxicidade.

\section{INTRODUÇÃO}

Um dos problemas decorrentes da degradação resultante do manejo inadequado das pastagens é a infestação mais acentuada por plantas daninhas. Na competição pelos fatores de crescimento, as plantas daninhas promovem queda da capacidade de suporte da pastagem, aumentando o tempo de

\footnotetext{
${ }^{1}$ Universidade Camilo Castelo Branco - UNICASTELO - Área de agronomia, fitotecnia e manejo de plantas daninhas
} 
formação e de recuperação do pasto (ANDRADE, 2007).

As plantas daninhas podem prejudicar ainda a eficiência de utilização da forragem, prejudicando assim a eficiência no sistema de produção (GOULART et al.,2007). Além disso, os animais bovinos e algumas espécies de ruminantes evitam pastejar em áreas infestadas por plantas daninhas (Goulart e Corsi, 2009).

Entre as plantas daninhas, o gênero Sida apresenta mais de 170 espécies. As diversas espécies de Sida são conhecidas no Brasil pelo nome vulgar de "guanxumas". Existem algumas espécies de plantas de outros gêneros, e mesmo de outras famílias botânicas, que apresentam certa semelhança com plantas do gênero Sida, e que podem ser tratadas como "guanxumas" (CONSTANTIN et al., 2007).

A espécie (Sida glaziovii), vulgarmente conhecida com guanxuma branca, apresenta-se como uma planta perene, fibrosa, ereta ou sub-prostrada, de $30-70 \mathrm{~cm}$ de altura. Caule revestido por pubescência esbranquiçada e suas folhas lanuginosas. Sua reprodução ocorre por sementes e suas flores são brancas (LORENZI, 2006). Toleram solos ácidos e fracos, mas desenvolvem-se melhor em solos de maior fertilidade e de textura mais argilosa. (CONSTANTIN et al., 2007).

O estabelecimento de estratégias que possibilitem reduzir o grau de infestação de plantas daninhas nas pastagens, mantendo a longevidade produtiva, em níveis aceitáveis na infestação, é fundamental para a sobrevivência da atividade na região e para a sua lucratividade (EMBRAPA, 2006).

O controle químico exerce ação corretiva sobre o problema, permitindo o desenvolvimento da forrageira e seu aproveitamento pelos animais. Este controle químico consiste no uso de produtos químicos denominados herbicidas, que provocam a morte ou cessam o desenvolvimento de plantas daninhas. Além de ser o método mais utilizado por sua praticidade e menor custo no controle das plantas daninhas (NUNES, 2001; CASTRO JUNIOR; FERNANDES; ROSSI JUNIOR, 2008).

Os herbicidas de atividade auxínica são amplamente usados na agricultura. Os herbicidas mimetizadores de auxina mais importantes incluem os ácidos clorofenóxi (ex. 2,4-D), ácidos benzóicos (dicamba), piridinas (picloram, aminopiralide, triclopir e fluroxipir) e os ácidos quinolina carboxílicos (quinmerac, quinclorac). Eles basicamente mimificam os efeitos de concentrações de auxinas endógenas. (CATANEO e CARVALHO, 2008). No Brasil dos herbicidas registrados para pastagens, destacam-se o picloram, picloram em mistura com fluroxipir ou em mistura com 2,4D (RODRIGUES e ALMEIDA, 2005).

Esses herbicidas controlam plantas daninhas, dicotiledôneas, herbáceas e semi-arbustivas, em torno de 20 a 40 dias após a emergência quando estiverem em pleno desenvolvimento vegetativo (BARRETTO FILHO E SILVA, 2011).

Os efeitos iniciais nas plantas dicotiledôneas sensíveis são caracterizados por anormalidades no crescimento, tais como, epinastia e inibição do crescimento com intensificação da pigmentação verde foliar. Estes efeitos são seguidos por dano nos cloroplastos, causando clorose e destruição da integridade das membranas e do sistema vascular, e posterior dessecação e necrose dos tecidos (CATANEO e CARVALHO, 2008).

O objetivo do presente trabalho foi avaliar a ação de herbicidas mimetizadores de auxina no controle da guanxuma branca em área de pastagem com Urochloa decumbens.

\section{MATERIAL E MÉTODO}

O experimento foi desenvolvido no período de 31 de janeiro a 02 de março de 2013, em área de pastagem pertencente à Chácara Nossa Senhora Aparecida, no município de Cardoso, SP, nas coordenadas $20^{\circ} 05^{\prime} 34,62^{\prime \prime} \mathrm{S}$ e 49॰54'31,16” W, com 430 metros de altitude. 
Conforme a classificação climatológica de Köppen-Geiger a região é classificada como Aw, região com clima tropical (chuvas no verão), e com estação seca de inverno, forte precipitação anual (superior à evapotranspiração potencial anual), (CLASSIFICAÇÃO CLIMÁTICA DE KÖPPENGEIGER, 2017).

O delineamento experimental foi em blocos casualizados com cinco tratamentos, e quatro repetições (Tabela 1). Cada parcela constou de $5 \mathrm{~m}$ de comprimento e $5 \mathrm{~m}$ de largura, totalizando $25 \mathrm{~m}^{2}$ de área aplicada. A área total do experimento (20 parcelas) foi de $500 \mathrm{~m}^{2}$. Entre o meio dos blocos foi mantido um corredor de 3 metros de largura para o transito da máquina.

Tabela 1. Tratamentos utilizados no experimento com os herbicidas aplicados e as respectivas doses de ingrediente ativo e produto comercial por hectare. Chácara Nossa Senhora Aparecida, Cardoso, SP, 2013.

\begin{tabular}{|c|c|c|c|}
\hline Tratamentos (Produto comercial) & Ingrediente ativo & \multicolumn{2}{|c|}{ Dose/ha } \\
\hline & & $\mathrm{g} \mathrm{L}^{-1} \mathrm{i}$ & o. c. \\
\hline 1. Testemunha & - & - & - \\
\hline 2. Truper & Triclopir+Fluroxipir & $240+80$ & 4,0 \\
\hline 3. Jaguar & Aminopiralide+2,4D & $40+320$ & 2,5 \\
\hline 4. Tordon & 2,4D+Picloram & $240+64$ & 4,0 \\
\hline 5. Dominum & Aminopiralide+Fluroxipir & $40+80$ & 2,5 \\
\hline
\end{tabular}

Fonte: Do próprio autor.

i. = ingrediente ativo do herbicida contido na formulação comercial; p. c. = produto comercial

Os herbicidas utilizados no experimento apresentam as seguintes características, segundo Rodrigues e Almeida (2011):

Truper - É um herbicida seletivo e sistêmico, recomendado para o controle de plantas infestantes de folhas largas, semiarbustivas e arbustivas em áreas de pastagens de gramíneas forrageiras, como Brachiaria humidicola, Brachiaria brizantha, Brachiaria decumbens, Panicum maximum, Paspalum notatum, Cynodon plectostachyus, Ingrediente ativo Triclopir+Fluroxipir, presente na concentração de $240+80 \mathrm{~g} \mathrm{~L}^{-1}$, na formulação do tipo concentrado emulsionável;

Jaguar - É um herbicida recomendado para o controle de dicotiledôneas indesejáveis em pastagens, ingrediente ativo Aminopiralide+2,4D, presente na concentração de $40+320 \mathrm{~g} \mathrm{~L}^{-1}$, na formulação do tipo concentrado solúvel;

Tordon - É um herbicida recomendado para o controle de dicotiledôneas indesejáveis de porte arbóreo, arbustivo e subarbustivo em pastagens e para a erradicação de touças de eucalipto na reforma de áreas florestais, ingrediente ativo 2,4D+Picloram, presente na concentração de $240+64 \mathrm{~g} \mathrm{~L}^{-1}$, na formulação do tipo concentrado solúvel.

Dominum - É um herbicida seletivo, de ação sistêmica e pós-emergente indicado para controle de plantas daninhas em pastagem, ingrediente ativo Aminopiralide+Fluroxipir, presente na concentração de $40+80 \mathrm{~g} \mathrm{~L}^{-1}$, na formulação do tipo Emulsão Água em Óleo.

As aplicações dos herbicidas foram tratorizadas, realizadas com trator Massey Ferguson 275 acoplado com um pulverizador de barras Jacto Condor de 600 litros de capacidade, trabalhando com uma velocidade de 4,2 $\mathrm{km} \mathrm{h}^{-1}$ e uma pressão de $45 \mathrm{lb} \mathrm{pol}^{-2}$ e com barra equipada com vinte quatro pontas do tipo leque, marca Teejet 110.02 (XR), espaçados de $0,5 \mathrm{~m}$. O volume de calda aplicado foi de $324 \mathrm{~L} \mathrm{ha}^{-1}$. 
As aplicações foram realizadas em pós-emergência das plantas de guanxuma, em pleno desenvolvimento vegetativo. A todos os tratamentos foi adicionado o adjuvante Aterbane $0,3 \% \mathrm{v} / \mathrm{v}$ exceto na testemunha.

$\mathrm{Na}$ ocasião da aplicação dos tratamentos foi verificado na área ventos em torno de $3 \mathrm{~km} \mathrm{~h}^{-1}$; o tempo estava nublado; a temperatura do ambiente, observada no início das aplicações foi de $29^{\circ} \mathrm{C}$ e UR do ar de 57\%. - (Figura 1).

Figura 1. Estádio de desenvolvimento das plantas de guanxuma no dia da aplicação dos tratamentos.

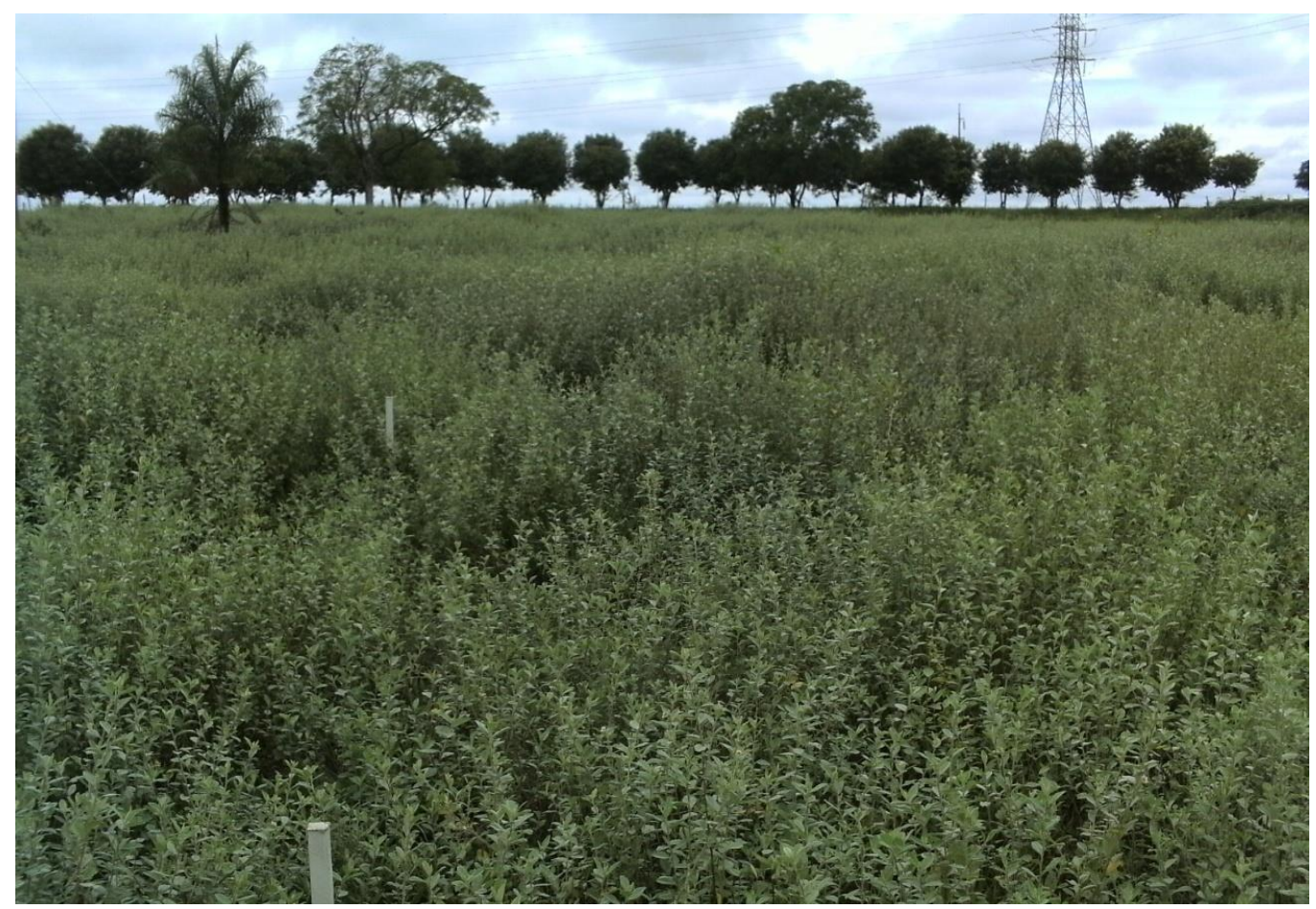

Fonte: Do próprio autor

A eficiência dos herbicidas no controle da planta daninha foi avaliada aos 5, 10, 15, 20, 25 e 30 dias após a aplicação (DAA), baseado em uma escala visual de controle, onde $0 \%=$ nenhum controle das plantas daninhas e $100 \%=$ controle total das plantas daninhas. Considerou-se eficiente o controle igual ou superior a $80 \%$. A seletividade dos tratamentos às plantas da cultura foi avaliada visualmente, considerando-se a biomassa e a coloração das plantas tratadas, comparadas com as plantas da testemunha (SBCPD, 1995).

Os dados foram submetidos a análise de variância pelo teste de Tukey a 5\% de probabilidade.

\section{RESULTADO E DISCUSSÃO}

Verificou-se que todos os tratamentos, com exceção da testemunha, apresentaram índices de controle igual ou acima de $90 \%$ aos 30 DAA. Os melhores índices de controle foram obtidos com os herbicidas Truper e Dominum, nas doses comerciais. 
Tabela 2. Porcentagem de controle aos $5,10,15,20,25$ e 30 dias após a aplicação (DAA), em área de pastagem com infestação de Guanxuma, Cardoso-SP, 2013.

\begin{tabular}{l|llllll}
\hline \multicolumn{1}{c|}{ Tratamentos } & \multicolumn{5}{c}{ \% Controle } \\
\hline Produto & $5 \mathrm{DAA}$ & $10 \mathrm{DAA}$ & $15 \mathrm{DAA}$ & $20 \mathrm{DAA}$ & $25 \mathrm{DAA}$ & $30 \mathrm{DAA}$ \\
Testemunha & $0,0 \mathrm{a}$ & $0,0 \mathrm{a}$ & $0,0 \mathrm{a}$ & $0,0 \mathrm{a}$ & $0,0 \mathrm{a}$ & $0,0 \mathrm{a}$ \\
Truper & $88,75 \mathrm{~b}$ & $96,50 \mathrm{ab}$ & $100,0 \mathrm{a}$ & $100,0 \mathrm{a}$ & $100,0 \mathrm{a}$ & $100,0 \mathrm{a}$ \\
Jaguar & $53,25 \mathrm{~d}$ & $67,50 \mathrm{c}$ & $77,0 \mathrm{~b}$ & $81,25 \mathrm{~b}$ & $91,25 \mathrm{a}$ & $97,75 \mathrm{a}$ \\
Tordon & $47,50 \mathrm{e}$ & $62,50 \mathrm{~d}$ & $71,25 \mathrm{c}$ & $80,0 \mathrm{~b}$ & $91,50 \mathrm{a}$ & $96,25 \mathrm{a}$ \\
Dominum & $79,0 \mathrm{c}$ & $84,50 \mathrm{bc}$ & $93,0 \mathrm{ab}$ & $96,75 \mathrm{a}$ & $100,0 \mathrm{a}$ & $100,0 \mathrm{a}$ \\
CV $(\%)$ & 6,0569 & & & & & \\
DMS (\%) & 3,3376 & & & & & \\
\hline
\end{tabular}

Fonte: Do próprio autor.

DAA = Dias após a aplicação. Médias seguidas de mesma letra minúscula na coluna, não diferem entre si pelo teste de Tukey a $5 \%$ de probabilidade.

Aos 10 DAA o herbicida Truper já apresentava controle total sobre as plantas na parcela, e o herbicida Dominum aos 15 DAA apresentava o mesmo efeito. Os herbicidas Jaguar e Tordon obtiveram controle total das plantas aos 25 DAA.

Não foram observados danos de intoxicação nas plantas de Urochloa brizantha aos 05, 10, 15, 20, 25 e 30 dias após a aplicação (DAA). Santos et al. (2006) avaliando a eficácia dos herbicidas 2,4-D + picloram (Tordon), fluroxypyr + picloram (Plenum) e triclopyr (Garlon), aplicados em pulverização foliar em área total, no controle de aroeirinha (Schinus terebintifolius) e de mata-pasto (Eupatorium maximilianii) em pastagem, concluíram que todos os herbicidas utilizados foram eficientes no controle das invasoras, sem causar intoxicação na pastagem.

Os herbicidas Truper e Dominum, já apresentam controle satisfatório ente 80-89\% logo aos 5 DAA e com 15 DAA as plantas de guanxuma apresentavam-se com 90-100\% de controle (tabela 2). Resultado semelhante foi obtido por Ladeira Neto et al. (2010). Analisando os dados verifica-se que todos os tratamentos, com exceção da testemunha, apresentaram índices de controle igual ou acima de $80 \%$, aos 20 DAA.

Santos, Santana e Melo (2011), avaliaram a eficácia dos herbicidas Padron (picloram), Togar (triclopir+picloram) e Tordon (2,4-D+picloram) no controle pós-emergente de Jurubeba (Solanum paniculatum) em pastagem de Brachiaria spp, em comparação ao controle mecânico. Foram realizadas avaliações visuais de controle de (0 a 100\%) aos 04, 12 e 31 dias após a aplicação (DAA). Os autores verificaram que os herbicidas Padron (picloram) e Tordon (2,4-D+picloram) promoveram 100\% de controle da espécie, e o herbicida Togar TB (triclopir+picloram) promoveu um controle de $85 \%$.

Realizando um trabalho de avaliação de eficácia e seletividade de herbicidas em misturas com Stimulate $^{\mathrm{r}}$ no controle de plantas daninhas em pastagem de Panicum maximum jacq vr. Aruana, Barros Junior e Maciel-(2008), definiram como eficientes os herbicidas Dominum (fluroxipir+aminopiralide), Grazon (2,4-D+picloram), Jaguar (2,4-D+aminopiralide), Tordon (2,4-D+picloram) e DMA 806 (2,4-D), que controlaram as plantas daninhas malva-branca (Sida cordifolia), caruru (Amaranthus viridis), ervaquente (Spermacoce latifolia) e beldroega (Portulaca oleracea).

Os herbicidas Jaguar e Tordon obtiveram controle de $80 \%$ a partir dos 20 dias. Tinazo et al. (2006), avaliaram a eficácia do produto à base de 2,4-D+Picloram no controle de invasoras em pastagens da região de Colinas do Tocantins-TO, e verificaram, que o controle das plantas daninhas não foi eficiente 
para todas as espécies, sendo que em algumas situações, como o gervão (Heliotropium indicum), a vassourinha (Anoda cristata) e a quatro - quina (Coutarea hexandra), detectou-se uma baixa eficiência de controle (20-30\%), enquanto que a guanxuma foi controlada com sucesso (60-90\%).

\section{CONCLUSÃO}

Conclui-se que os herbicidas Truper, Jaguar, Tordon e Dominum nas doses recomendadas foram eficientes no controle da guanxuma branca Sida glaziovii.

\section{REFERÊNCIAS}

ANDRADE D. A. Caracterização morfológica e citogenética de sementes e plântulas de algumas espécies de plantas tóxicas. Dissertação (Mestrado), Jaboticabal - SP, 2007.

BARRETTO FILHO, J. A. B.; SILVA, A. M. Eficiência do uso de herbicidas sistêmicos em recuperação de pastagens. Cadernos de pós-graduação da FAZU, v. 2. 2011.

BARROS JUNIOR, J. F. F.; MACIEL, C. D. G. Eficácia e Seletividade de Herbicidas em Misturas com Stimulate no Controle de Plantas Daninhas em Pastagem de Panicum maximum jacq vr. Aruana.

Sociedade Brasileira da Ciência das Plantas Daninhas, Boletim Informativo, v.14, n.3, p.16, 2008.

CLASSIFICAÇÃO CLIMÁTICA DE KÖPPEN-GEIGER. Disponível em:

http://portais.ufg.br/uploads/68/original Classifica o Clim tica Koppen.pdf, acessado dia 02/09/2017.

CASTRO JUNIOR, T. G.; FERNANDES, A.C.; ROSSI JUNIOR, P. Herbicidas no manejo de invasoras em pastagem de Brachiaria brizantha cv marandu, no Mato Grosso. Revista Acadêmica, v.6, n.1, p.109$118,2008$.

CONSTANTIN, J. et al. Controle de diferentes espécies de guanxuma com aplicações seqüenciais de flumiclorac-pentil. Revista Acta Scientiarum Agronomy, v. 29, n. 4, p. 475-480, 2007.

CATANEO, A.C.; CARVALHO, J. C. Resistência de plantas a herbicidas mimetizadores das auxinas (grupo 0). Aspectos de resistências de herbicidas a plantas daninhas. HRAC-BR, Piracicaba/SP, Ed. $3^{\mathrm{a}}$, Cap. 04, p. 62, 2008.

EMBRAPA, Manejo de plantas daninhas em pastagens cultivadas. In: HOMMA, A. K. O. et al. Criação de bovinos de corte no estado do Pará. Sistemas de Produção - 3, Belém, dez. 2006.

GOULART, R. C. D. et al. In: Plantas daninhas influenciando a morfologia do capim colonião (Panicum maximum). $44^{a}$ Reunião da Sociedade Brasileira de Zootecnia. Jaboticabal, 2007. Anais da $44^{a}$ Reunião anual da Sociedade Brasileira de Zootecnia, 2007.

GOULART, R. C. D. ; CORSI, M.; Efeito da planta daninha na utilização da forragem pelos animais. Informativo Técnico n01 - Piracicaba/SP: Projeto CAPIM-Pesquisa e Extensão; Departamento de Zootecnia; ESALQ-USP, p. 6, 2009.

LADEIRA NETO A.et al. Controle de Attalea speciosa com misturas de fluroxypyr + triclopyr aplicados na gema central em pastagens de Brachiaria brizantha, In: XXVII Congresso Brasileiro de Ciência das Plantas Daninhas. Ribeirão Preto. Palestras CD, 2010. 
LORENZI, H. Manual de Identificação e Controle de Plantas Daninhas: plantio direto e convencional. 6. ed. Nova Odessa: Instituto Plantarum, 2006.

NUNES, S. G. Controle de Plantas Invasoras em Pastagens Cultivadas nos Cerrados. Documentos 117 Campo Grande: Embrapa, p. 32, 2001.

RODRIGUES, B. N.; ALMEIDA, F. S. Guia de Herbicidas. 5. ed. Londrina, PR, 2005. 591 p.

RODRIGUES, B. N.; ALMEIDA, F. S. Guia de herbicidas. 6. ed. Londrina, PR, 2011. 697 p.

SANTOS, M. V.et al. Eficácia e persistência no solo de herbicidas utilizados em pastagem. Planta daninha, v. 24 nº. 2. Viçosa, MG, Abril./Junho 2006.

SANTOS, N. V.; SANTANA, A. C. G.; MELO M. B. Controle de Solanumpaniculatum l. em Pastagens de Brachiaria spp. no município de Nossa Senhora do Socorro (SE). Cadernos de graduação ciências biológicas e da saúde, v.13, n.14, p.25-34, 2011.

SBCPD - Sociedade brasileira da ciência das plantas daninhas. Procedimentos para instalação, avaliação e análise de experimentos com herbicidas. Londrina: 1995.42 p.

TINAZO, V. A.et al. Avaliação da eficácia de produto à base de 2,4-D+Picloram no controle de invasoras em pastagens da região de Colinas do Tocantins-TO. In: $14^{\circ}$ Simpósio Internacional de Iniciação Científica da USP - SIICUSP, 2006, Piracicaba/SP. Anais do 14 Simpósio internacional de iniciação científica da USP SIICUSP, 2006. 